\title{
Supervisão pedagógica no contexto da formação inicial de educadores de Infância: modelo de formação em alternância
}

\section{Pedagogical supervision in the context of the formation of childhood educators: an alternating training model}

Isabel, Maria Tomázio Correia

Escola Superior de Educação, Instituto Politécnico de Setúbal

Setúbal, Portugal

isabel.correia@ese.ips.pt

Maria, Manuela de Sousa Matos

Escola Superior de Educação, Instituto Politécnico de Setúbal

Setúbal, Portugal

maria.sousa.matos@ese.ips.pt

Sofia, Gago da Silva Corrêa Figueira

Escola Superior de Educação, Instituto Politécnico de Setúbal

Setúbal, Portugal

sofia.figueira@ese.jps.pt

$02 / 10 / 2020$

RESUMO: Neste artigo apresentamos o modelo de supervisão pedagógica em contexto de formação de educadores de infância, integrado no Mestrado em Educação Pré-Escolar da Escola Superior de Educação (ESE) do Instituto Politécnico de Setúbal (IPS), bem como as perceções de estudantes estagiários e educadores cooperantes, sobre a sua organização e desenvolvimento. É um modelo de formação com uma organização em alternância, que alterna tempos de prática pedagógica com tempos de permanência na escola de formação, num processo de construção de conhecimentos, assente numa perspetiva dialógica e construtivista que inclui todos os intervenientes no processo de formação, composto 
pela tríade - estagiários, educadores cooperantes do local de estágio e supervisores da escola de formação. Enfatiza-se, de forma gradual, o valor da prática pedagógica enquanto componente básica de análise e reflexão dos estudantes estagiários, com o objetivo de adquirirem competências pessoais e profissionais. A organização do plano curricular contempla uma perspetiva integradora das diferentes componentes de formação prevista no decreto-lei 79/2014. Os estudantes estagiários e os educadores cooperantes ao avaliarem o modelo, referem que consiste numa forma de organização e desenvolvimento positiva e fazem referência aos tempos de alternância - contexto de estágio e escola de formação - como uma mais-valia para o desenvolvimento profissional dos futuros educadores de infância, aludindo que os mesmos têm a possibilidade de questionarem a prática e adotarem uma atitude reflexiva, ou seja, têm a possibilidade de efetivar o ciclo observar-agir-refletir. Evidenciam, ainda, os processos colaborativos e experienciais vivenciados pelos estudantes estagiários, como aspetos necessários e influentes na construção da teoria a partir da prática.

PALAVRAS-CHAVE: supervisão pedagógica, formação inicial, educadores de infância, práticas pedagógicas, educadores cooperantes.

ABSTRACT: In this article we present the model of pedagogical supervision in the context of the formation of childhood educators, integrated in the Master's Degree in Pre-School Education of the School of Education (ESE) of the Polytechnic Institute of Setúbal (IPS), as well as the perceptions of trainee students and educators, on their organization and development. It is a training model with an alternating organization, which alternates times of pedagogical practice with times of permanence in the training school, in a process of knowledge construction, based on a dialogic and constructivist perspective that includes all the participants in the formation process, composed by the triad - trainees, cooperating educators of the training place and supervisors of the training school. Gradual emphasis is placed on the value of pedagogical practice as a basic component of the analysis and reflection of the trainee students, with the aim of acquiring personal and professional skills. The organization of the curricular plan contemplates an integrative perspective of the different training components provided for in Decree-Law 79/2014. The trainee students and the cooperating educators, when evaluating the model, refer that it consists of a form of positive organization and development and refer to alternating times - training context and training school - as an added value for the professional development of the future educators of childhood, alluding that they have the possibility of questioning the practice and adopting a reflexive attitude, they have the possibility of effecting the cycle observe-act-reflect. 
They also show the collaborative and experiential processes experienced by trainee students, as necessary and influential aspects of the construction of theory from practice.

KEYWORDS: pedagogical supervision, initial training, childhood educators, pedagogical practices, cooperating educators.

\section{INTRODUÇÃO}

A componente de prática pedagógica, estágio, na formação inicial é reconhecida como fundamental na aprendizagem da profissão, na construção dos saberes profissionais e na construção do perfil de desempenho profissional (Altet, 2000; Zeichner, 2000; Zabalza, 2003). É uma temática que tem suscitado muito interesse na comunidade científica e como refere Roldão (2009) a "incidência no estudo das práticas e, em particular, da componente de prática pedagógica ou estágio no interior dos programas de formação" (p. 4), tem aumentado nos últimos anos. Face à relevância da prática pedagógica na formação inicial de educadores de infância/professores importa refletir sobre a sua conceção e organização, o que inclui a reflexão sobre os processos de supervisão.

Diferentes autores Marcelo-Garcia (1999), Canário (2002), Formosinho (2009), Altet (2004), Darling-Hammond (2006) entre outros, têm abordado, nas últimas décadas, os modelos de organização dos estágios na formação inicial dos educadores/professores. Dos modelos preconizados reconhecem o modelo em alternância como um modelo que, de uma forma global, possibilita uma relação consistente teoria/prática/teoria e permite uma organização assente em estratégias impulsionadoras de reflexividade. Altet (2004) define o princípio de alternância na formação inicial como a articulação dos momentos de estágio e a realização de momentos de reflexão sobre a prática na instituição de formação.

Segundo Matias e Vasconcelos (2010) "o modelo de supervisão na formação dos educadores de infância é em geral composto por um triângulo, constituindo-se com a figura do supervisor da escola de formação, o cooperante do local de estágio e o estagiário" (p. 20), reconhecendo a 
importância do supervisor da instituição de ensino superior e do educador cooperante, na formação dos futuros educadores de infância. Numa supervisão que se pretende reflexiva tanto o professor supervisor como o educador cooperante priorizam a reflexão sobre a ação, apoiando o estudante na construção da sua profissionalidade.

Reconhecendo que a "formação de professores não se pode fazer de modo desligado das escolas onde o futuro professor vai exercer as suas práticas" (Vasconcelos, 2009, p. 15), a organização dos estágios pressupõe a construção de uma cooperação entre a instituição de ensino superior e as instituições que recebem os estudantes estagiários, docentes da unidade curricular (UC) de estágio e educadores cooperantes.

Realça-se, neste artigo, o processo de avaliação do modelo - organização e dinamização das aulas, seminário, estágio - realizada por todos os envolvidos, professores, educadores cooperantes e estudantes estagiários, para a implementação de mudanças com efeitos na qualidade da formação inicial.

Mobilizam-se, assim, registos escritos dos educadores cooperantes e dos estudantes recolhidos nas referidas reuniões de avaliação das UC de Estágio (Educação de Infância I e II), inquéritos por questionário aos educadores cooperantes e aos estudantes e, ainda, excertos incluídos nos Dossiers Pedagógicos, elaborados pelos estudantes, como produto final de avaliação. Procedeu-se à análise e interpretação da informação recolhida através da técnica de análise de conteúdo, identificando aspetos positivos e constrangimentos na organização e funcionamento do modelo e a importância atribuída à função do educador cooperante junto dos estudantes.

\section{PRÁTICA DE ENSINO SUPERVISIONADA: ORGANIZAÇÃO E FUNCIONAMENTO}

O plano de estudos do Mestrado em Educação Pré-Escolar (MEPE) da Escola Superior de Educação do Instituto Politécnico de Setúbal (ESE/IPS) está enquadrado pelo Decreto-lei 79/2014, de 14 de maio.

O plano de estudos organiza-se de forma a favorecer a articulação 
teoria/prática/teoria em que "a teoria informa a prática e esta, por sua vez, ilumina os quadros teóricos porque existe um aprofundamento cada vez maior e uma observação cada vez mais fina" (Alarcão \& Tavares, 2003, p. 31), considerada fundamental no processo de formação profissionalizante.

Com base no que está definido nas Normas Regulamentares dos Cursos de Mestrado em Educação e Ensino da ESE/IPS, a estrutura curricular segue uma orientação em alternância interativa (Artigo 9. ${ }^{\circ}$ ).

Esta alternância interativa é uma tradição que teve origem nos cursos de formação inicial de educadores de infância na ESE/IPS, em 1987, o que na altura foi considerado uma inovação. Neste modelo, a prática é realizada ao longo da formação, os estudantes transitam entre dois contextos, a instituição de ensino superior e o contexto de estágio (valência de creche e jardim de infância), com a possibilidade de articularem situações de formação e situações da prática, promovendo uma maior relação teoria/prática/teoria, privilegiando a intervenção e uma atitude reflexiva.

Sublinha-se que só é possível construir uma atitude reflexiva a partir da reflexão crítica dos acontecimentos reais, onde são valorizados os saberes construídos pela experiência ou "savoirs pratiques" (Altet, 2004, p.103). Revimos nesta organização ideias veiculadas por Canário (2000), que encara a situação de formação inicial em alternância como um vai e vem entre ideias e experiências, entre a teoria e a prática, no pressuposto de que os professores aprendem a sua profissão nos contextos educativos.

Nesta perspetiva as Unidades Curriculares de estágio, Estágio em Educação de Infância I e Estágio em Educação de Infância II (1.ํo e 2.ำ semestre), integradas na componente de formação PES do $1 .^{\circ}$ ano do Mestrado em Educação Pré-Escolar, estão organizadas em dois momentos de estágio, com a duração de 10 semanas em cada semestre.

No 1. semestre os estudantes realizam o estágio em contexto de creche em instituições com diferentes suportes jurídicos (rede social e rede privada). No 2.9 semestre as estudantes realizam o estágio em contexto de jardim de infância, em instituições com os mesmos suportes jurídicos, acrescido da rede pública. Os estudantes, em ambos os semestres, permanecem em estágio duas semanas, de segunda a sexta-feira, e oito semanas de segunda a quartafeira, cinco horas por dia, num total de 170 horas por semestre. 
A compreensão desta organização, enquanto modelo de alternância, é percecionada de forma diferente pelas educadoras cooperantes. Apesar da maioria compreender e identificar aspetos positivos na organização e desenvolvimento do estágio, a opinião não é, contudo, unânime. Nas palavras das educadoras cooperantes:

Considero estes dois dias de aulas, imprescindíveis, numa perspetiva de parceria e complementaridade com a experiência do estágio (Educadora R, Questionário, 2018).

Sinto que de facto é-lhes fundamental parar para refletir na escola de formação sobre aquilo que vai acontecendo no estágio. Contudo, penso que idealmente esta paragem deveria ser de apenas um dia e não de dois, uma vez que acaba por ser praticamente metade da semana o fio e condutor (Educadora S, Questionário, 2018)

A calendarização da prática pedagógica não é a melhor (....) assim como a distribuição da carga horária (semanas de 3 dias, semanas de 5) que inviabiliza a perceção do trabalho desenvolvido no préescolar (Educadora A, Questionário, 2018).

Relativamente ao entendimento desta mesma questão, por parte dos estudantes, ela não é de imediato compreendida como uma mais-valia. Os estudantes quando ingressam no mestrado, depois de terem frequentado uma Licenciatura em Educação Básica (LEB) de "banda larga", com uma prática pedagógica diminuta, manifestam um grande interesse e alguma ansiedade para se integrarem, de imediato, nos contextos de estágio.

Num estudo realizado por Figueira (2017), conclui-se que a maioria dos estudantes quando entram na LEB têm como expectativa iniciar, logo no 1.으. ano da licenciatura, a prática profissional (IPP) e esperam que esta componente de formação acompanhe todo o percurso da licenciatura, mas, tal situação não se verifica devido ao número de créditos que são atribuídos por lei à IPP. Ao ingressarem no mestrado, naturalmente, constata-se que há uma sobrevalorização da prática em detrimento da teoria, situação que remete para uma apreciação inicial pouco positiva, no que respeita ao modelo de alternância e aos tempos de permanência na Escola como se pode verificar pelas seguintes opiniões:

(...) quando as professoras nos disseram que depois da segunda semana tínhamos aulas às quintas e sextas feiras fiquei triste. Queria estar todos os dias no estágio, queria tanto, há três anos que 
esperava pelo estágio. Queria estar com os meninos e meninas, com a educadora $\mathrm{X}$ e a equipa pedagógica. Agora que o estágio acabou percebo a importância de irmos à escola duas vez por semana. As aulas foram muito produtivas. Agora já sei a importância de refletir, questionar, observar e fazer relação teoria, prática e teoria e a importância dos momentos com as professoras e colegas (Estudante C, Dossier Pedagógico, 2018).

O período de estágio é um pouco reduzido pois dois meses de prática (apenas três vezes por semana) é relativamente pouco tempo para termos a possibilidade de "experienciar" de forma aprofundada o contexto em que somos inseridas para que possamos adquirir aprendizagens significativas para 0 nosso futuro enquanto profissionais da educação (Estudante D, Questionário, 2018).

Durante dois dias, quinta e sexta-feira, os estudantes têm aulas na ESE, incluindo duas horas e meia de seminário em turma ou em pequeno grupo com o docente da UC de estágio. O seminário é um espaço centrado na partilha e reflexão que permite aos estudantes questionarem a prática e adotarem uma postura reflexiva com o apoio dos docentes da UC e supervisores de estágio.

Com a continuidade da experiência de participação no seminário, estes momentos de reflexão tornam-se significativos, sendo referidos como momentos cruciais nos seus percursos:

(...) realço a relevância dos momentos de reflexão na ESE com os orientadores de estágios, este é um momento que sinto como um local seguro para partilharmos inseguranças e acontecimentos vivenciados, aos quais por vezes podemos não nos sentir tão à vontade em fazê-lo com a educadora cooperante. O facto de estes momentos serem realizados com a restante turma também é uma mais-valia, permitindo uma troca e partilha de ideias e, muitas das vezes, são as próprias colegas que nos ajudam a refletir sobre certos temas/situações (Estudante A, Dossier Pedagógico, 2018).

(...) as aulas de reflexão na escola foram momentos muito importantes. Ir à ESE todas as semanas para pensarmos a prática, com a professora e as colegas foram momentos muito ricos. Voltava à sala na $2^{\mathrm{a}}$ feira mais segura e com maior capacidade de observação e de problematização da prática (Estudante B, Dossier Pedagógico, 2018).

As aulas disponibilizadas para reflexão dos estágios são fundamentais [...] onde as estudantes se reuniam em pequenos grupos com o seu orientador. Foi notória a partilha e à vontade em 
referir determinados assuntos, como também havia uma maior ajuda por parte do orientador (Estudante, M, Questionário, 2018).

Nos contextos de estágio cada estudante é apoiado por um educador cooperante que aceita participar no processo de formação dos estudantes. Os educadores cooperantes, de acordo com o Decreto-Lei 79/2014, de 14 de maio, são os docentes que colaboram na formação como orientadores e devem ter formação e experiência adequadas às funções a desempenhar e prática docente não inferior a cinco anos (Artigo 23.., n.ำ 1 e n.. 2 ).

Estes profissionais são entendidos como formadores do terreno e, tal como os docentes supervisores, tem um papel fundamental na formação do estudante. A ESE/IPS tem uma rede consistente de educadores cooperantes, a maioria dos quais com uma larga experiência profissional e de cooperação com a ESE/IPS, o que foi considerado um ponto forte no Relatório de Apresentação do pedido - novo ciclo de estudos (NCE/14/00996) à Agência de Avaliação e Acreditação do Ensino Superior (A3ES) e facilita o processo de supervisão, nomeadamente a relação, o diálogo, a comunicação, aspetos que se reconhecem como determinantes no processo vivenciado pelos estudantes e no trabalho de parceria entre todos os intervenientes.

\section{A SUPERVISÃO PEDAGÓGICA: UM PROCESSO COOPERADO}

O modelo de supervisão na formação inicial dos educadores da ESE/IPS assenta na tríade envolvida na supervisão de práticas - estudante/docente da UC de estágio/educador cooperante. Quer o docente da UC de estágio, quer o educador Práticas Educativas e Supervisão Pedagógica 783 cooperante têm um papel fundamental na formação dos estagiários, o que exige um trabalho bem estruturado e organizado por parte da instituição de ensino superior.

Revemo-nos na definição de supervisão de Oliveira-Formosinho (2002), no âmbito do modelo ecológico de supervisão, como um processo sistemático em que uma candidata a educadora recebe apoio, suporte e orientação de uma educadora mais experiente e especializada para fazer a sua aprendizagem profissional, em diálogo-comunicação com a instituição em que a aluna se está a formar (p.116). 
Salienta-se aqui a importância da cooperação entre os contextos de estágio e a instituição de ensino superior, sendo as parcerias reconhecidas como fundamentais para que um programa tenha êxito (Santos, 2015). A existência de uma bolsa consistente de educadores cooperantes que colaboram com a escola há vários anos, facilita a comunicação e a efetivação de parcerias.

Estas parcerias alicerçam-se numa continuidade de trabalho, potenciando um conhecimento sustentado sobre as dinâmicas formativas das diferentes instituições em presença. Os educadores cooperantes reconhecem os modos de funcionamento e os objetivos formativos da ESE/IPS, mostrando-se disponíveis e implicados no acolhimento dos estagiários, o mesmo acontecendo por parte dos docentes da ESE. Verifica-se uma disponibilidade total para a deslocação aos contextos, sempre que os educadores cooperantes e estudantes necessitem, promovendo diferentes estratégias de apoio (observação em sala, reuniões, conversas informais). São ainda realizadas, em cada semestre, duas reuniões de cooperantes, no início e final do estágio, para explicitar expectativas e intencionalidades, refletir sobre os documentos orientadores do estágio, partilhar e discutir os pareceres de avaliação e refletir sobre o processo formativo. Estas reuniões têm, habitualmente, uma assiduidade considerável e funcionam como espaços de desenvolvimento profissional.

Funcionam igualmente como espaços de desenvolvimento profissional, a dinamização de aulas na ESE por parte dos educadores cooperantes, em colaboração com os docentes, permitindo estabelecer relação com os estudantes, inteirarem-se dos conteúdos e dinâmicas desenvolvidas e partilharem as suas práticas pedagógicas. Esta metodologia permite, simultaneamente, estreitar relações entre a escola de formação e os contextos de estágio e teorizar a partir da prática. Acresce ainda a sua participação nas aulas abertas, organizadas pela equipa de docentes e dinamizadas por diferentes especialistas em função do tema a abordar, com a periodicidade mensal, reforçando o desenvolvimento profissional e a ligação com a ESE.

No que respeita à supervisão esta assume diferentes modalidades: seminário na ESE com os docentes; no local de estágio, somente com os educadores cooperantes e estagiários e com os educadores cooperantes, 
docentes e estagiários. Os seminários são momentos onde os professores reúnem com os estudantes em sessões de reflexão prospetiva e retrospetiva, através da análise prático-teórica das situações pedagógicas promovendo a reflexão sobre a intervenção. Adotar uma postura reflexiva é uma atitude que se vai construindo e que, muitas vezes, não é de imediato apreendida pelos estudantes.

Como refere Alarcão (1996) ter uma atitude reflexiva é muito mais que descrever o que aconteceu na sala, a experiência sendo fundamental na prática pedagógica, deve ser amadurecida pelo questionamento, enquanto estratégia de distanciação e reflexão sobre a mesma, processo difícil de ser construído. No seminário os estudantes são incentivados, e apoiados para questionarem e teorizarem a prática, dando significado às experiências vividas.

De igual forma, os educadores cooperantes e estudantes reúnem semanalmente para reflexão, nos contextos de estágio, dando continuidade a esta dinâmica. Estes espaços de reflexão incidem sobre as práticas educativas desenvolvidas pelos estudantes e visam a edificação do seu processo de formação/aprendizagem e da sua identidade profissional e contribuem igualmente e, de forma isomórfica, para o desenvolvimento profissional dos educadores cooperantes. Os testemunhos dos educadores cooperantes e dos estudantes transparecem essa perspetiva:

Penso que em conjunto, educador e estagiária adquirem maiores competências, pois em conjunto avaliamos. As nossas ações pedagógicas e didáticas do nosso dia-a-dia. É uma forma de se refletir sobre as nossas práticas. No fundo acabamos por aprender umas com as outras, as trocas de saberes, opiniões, são umas maisvalia quer paras as estudantes, quer para as educadoras (Educador B, Questionário, 2018).

(...) as estudantes poderem realizar as reflexões em conjunto com as educadoras cooperantes, pois estas podem enriquecer as reflexões e certificar-se de que as informações estão corretas (Estudante E, Questionário, 2018).

De qualquer modo, o educador será assim o elemento experiente que poderá dar ao aluno uma visão alargada dos desafios que irá enfrentar, ouvir as suas dúvidas e inquietações e essa é, apesar do trabalho acrescido, uma tarefa gratificante pois estamos de alguma forma a ajudar a formar um futuro profissional (Educadora $\mathrm{P}$, 
Questionário, 2018).

Salientamos aqui a preocupação dos docentes da ESE, respeitando o que está definido nos documentos orientadores e instituído no processo de formação, em sensibilizar os estudantes para a construção de práticas cooperadas com os educadores, no sentido de respeitarem o projeto pedagógico e educativo da instituição. Desta forma, procura-se que as propostas dos estudantes não "invadam" despropositadamente as dinâmicas educativas onde estão inseridos. A este respeito, vejamos as seguintes opiniões:

Como aspeto positivo o facto de os estagiários serem uma mais-valia, quer no trabalho mais individualizado com algumas crianças, quer nas dinâmicas de sala (que ficam enriquecidas), quer na avaliação do nosso desempenho. É importante esta visão externa do nosso desempenho, ajuda-nos a perceber as nossas lacunas e potencialidades e a crescer enquanto profissionais (Educadora $\mathrm{C}$, Questionário, 2018).

(...) sou mediadora entre a formação teórica e a formação prática, assumo o papel de modelo e de facilitadora da interação com as crianças e com todo o contexto educativo. Os locais de estágio são muitas vezes o primeiro contacto com a futura realidade dos estudantes e é muito gratificante poder transmitir-lhes o que de bom e de qualidade se pode fazer, mas mostrar também os riscos de uma intervenção errada, sem ser desmotivante ou inibidor da ação (Educadora A, Questionário, 2018).

(...) o facto de as planificações e atividades bem como o dia a dia no contexto de estágio ser em conjunto com a educadora, pois a partir de situações de trabalho em equipa o estudante pode preparar-se para o eventual trabalho em equipa que a profissão de educadora/ professora requererá (Estudante E, Questionário, 2018).

Os docentes realizam visitas de apoio e acompanhamento, pelo menos duas vezes, a cada estudante, em cada momento de estágio. O número de visitas é flexível e ajustado a cada situação, e pode ser solicitado a qualquer momento por qualquer um dos intervenientes. Com esta dinâmica pretende-se que o processo de supervisão seja reconhecido por todos como um processo colaborativo e de auto e hétero-aprendizagem

Por um lado, é dado espaço e tempo às alunas para se ambientarem no contexto de estágio e, por outro lado, o número de visitas é flexível e ajustado às necessidades da cooperante ou aluna, exemplo: 
sempre que solicitei a presença de orientadores em situações de estágio mais problemáticas o número de visitas foi de acordo com o solicitado (Educadora C, Questionário, 2018).

Ao longo destes anos de cooperante considero a supervisão das estagiárias adequada, por um lado é dado espaço e tempo as alunas para se ambientarem aos contextos de estágio, por outro lado, o número de visitas é flexível e ajustado às necessidades da cooperante ou aluna (Educadora E, Questionário, 2018).

Parece-me, então, pertinente referir que, as duas visitas aos contextos surgem como um apoio "crucial e personalizado", garantindo que acontece uma "mediação neutra" e um apoio "à compreensão pedagógica" de situações observadas/vividas e de eventuais, dificuldades/conflitos. No entanto, quero, também, elogiar a disponibilidade da Equipa de Professores da respetiva UC, para se deslocarem com mais frequência aos contextos, sempre que se justifique (...) As professoras com quem me tenho cruzado são muito participativas e conhecem de forma profunda a vida que vai acontecendo no estágio de cada uma das suas estagiárias, fazendo um acompanhamento próximo e genuíno (Educadora $\mathrm{R}$, Questionário, 2018).

A supervisão realizada em contexto assume um carácter essencialmente problematizador, pois considera-se que é na interação dialogante, que se constrói o conhecimento. As reuniões realizadas no final da manhã, ou tarde, apresentam-se como oportunidades de reflexão, sobre as situações observadas, dificuldades manifestadas e sucessos. São momentos e pontos de situação sobre o percurso realizado pelos estudantes, que contribuem para a construção da sua identidade profissional.

As reuniões no dia em que a Professora orientadora ia à creche foram muito importantes. Foram momentos em que as três falávamos da minha intervenção, das minhas dificuldades, das minhas angústias. Apesar de reunir semanalmente com a educadora $X$ falarmos sobre a minha intervenção, o meu estágio, os momentos com a Professora eram importantes e muito interessantes para a reflexão da prática (Estudante D, Dossier Pedagógico, 2018).

As reflexões cooperadas entre estagiária-educadora e estagiáriaeducadora-supervisor são um dos aspetos positivos da organização dos estágios uma vez que surgem partilhas de medos, receios, alguns objetivos já alcançados e são feitos balanços da nossa prestação nos contextos (Estudante M, Questionário, 2018). 
No contexto das reflexões cooperadas com a orientadora da escola o sentido das reflexões possibilitava uma maior abertura sobre 0 momento de estágio e até mesmo o trabalho como educadora, isto é, a minha perspetiva e identidade profissional (Estudante P, Dossier Pedagógico, 2018).

Cabe à instituição de ensino superior a formação dos estudantes tanto ao nível científico, como ao nível pedagógico, mas o estágio assume grande importância na formação inicial, daí a necessidade que os educadores têm de articular com os docentes da UC de estágio todas as informações sobre os estagiários.

Há, igualmente, uma disponibilidade total dos docentes da UC de estágio para apoiarem os educadores sempre que são solicitados, mesmo que não coincida com os dias das visitas de acompanhamento. Segundo Flores (2010) uma visão holística e articulada de formação implica um diálogo colaborativo e eficaz entre locais de estágio e escola de formação, no sentido de fomentar as potencialidades de cada uma das instituições. A criação de parcerias constitui uma questão essencial para congregar formadores de professores, orientadores/supervisores e futuros professores em exercício, com vista à superação da tradicional divisão entre "os práticos" e aqueles que teorizam, entre a investigação realizada pelos professores e a investigação conduzida em contexto académico.

Cabe aqui referir que, para além desta mediação conjunta formativa de futuros profissionais, docentes da UC de estágio e educadores cooperantes assumem diferentes funções no âmbito do apoio aos estudantes. Assim, ao docente cabe organizar e dinamizar as aulas antes dos períodos de estágio, preparar os momentos de estágio, fazer as colocações dos estudantes nos locais de estágio, fazer as visitas aos locais de estágio e reunir com o estudante e o educador cooperante no contexto, dinamizar os seminários e avaliar os dossiers pedagógicos, produto de avaliação da UC utilizado desde que foi implementado este modelo. Cabe igualmente preparar e dinamizar as reuniões de cooperantes na ESE.

O educador cooperante recebe o estudante na sua sala (creche/jardim de infância), é "reconhecido como formador no contexto educativo, é um facilitador/mediador das aprendizagens e dos progressos co construídos pelos 
estudantes" (Documento Orientador do Parecer Estágio, 2018/2019). Para além da participação nas reuniões de cooperantes estes profissionais acolhem os estudantes nas salas, partilham o seu trabalho, planificam em conjunto, refletem e discutem as potencialidades e fragilidades do quotidiano e avaliam o desempenho do estudante. Esta avaliação é partilhada com o estudante e o docente, discutindo, com transparência, o percurso realizado e as competências adquiridas. Reforça-se, à semelhança de todo o trabalho desenvolvido a dimensão colaborativa entre educador estudante e supervisor, de acordo com o apoio prestado ao longo da permanência nos contextos de estágio.

\section{CONSIDERAÇÕES FINAIS}

O modelo de formação em alternância preconizado no Mestrado em Educação Pré-Escolar da Escola Superior de Educação de Setúbal/IPS é percecionado pela maioria dos intervenientes em todo o processo formativo, como um modelo que permite a interação entre a teoria e a prática, privilegiando uma relação dialógica entre o ambiente profissional e o contexto de formação do ensino superior.

Este modelo em alternância, entre a escola de formação inicial e os contextos de estágio, ainda que nem sempre suficientemente entendido, permite o questionamento e problematização das situações vivenciadas pelos estudantes como uma mais-valia para o seu desenvolvimento profissional aludindo que os mesmos têm a possibilidade de questionarem a prática e adotarem uma atitude reflexiva, ou seja tem a possibilidade de efetivar o ciclo observar - agir - refletir.

Valoriza-se neste modelo a efetivação de formas de trabalho colaborativo entre todos os implicados, quer na preparação do estudante para intervir coerentemente e consistentemente no projeto educativo da instituição e no projeto pedagógico, de forma a respeitar todas as dinâmicas educativas implementadas pelo educador cooperante; quer na relação que se estabelece na tríade estudante/educador cooperante/docente da UC de estágio, registando-se uma permanente reflexão conjunta, tendo por base aspetos 
necessários e influentes para a construção da teoria a partir da prática. Procura-se, assim, apoiar o estudante nas necessidades, interesses e preocupações inerentes à sua ação pedagógica, bem como proporcionar uma crescente autonomia, para que a entrada na profissão seja feita de forma consciente, tranquila e entusiasmada.

Estamos em presença de um modelo que se alicerça numa perspetiva construtivista com o envolvimento de todos os implicados no processo de construção de saberes/competências na e pela ação, nos diferentes momentos de reflexão - seminário na ESE, reuniões entre estudante e educador cooperante e entre estudante, educador cooperante e docente da UC de estágio. Estes espaços de reflexão são cruciais, em nosso entender, para a construção da(s) identidade(s) de profissionais da pedagogia, considerados como especialistas agenciadores da relação, no âmbito da educação de infância.

\section{REFERÊNCIAS}

Alarcão, I. (1996). Formação reflexiva de professores: Estratégias de supervisão. Porto: Porto Editora.

Alarcão, I., \& Tavares, J. (2003). Supervisão da prática pedagógica: Uma perspetiva de desenvolvimento e aprendizagem (2..$^{\text {a }}$ ed.). Coimbra: Livraria Almedina.

Altet, M. (2000). Análise das práticas dos professores e das situações pedagógicas. Porto: Porto Editora.

Altet, M. (2004). L'analyse des pratiques en formation initial des enseignants: Develloper une pratique reflexive sur et pour l'action. Éducation Permanent, 160, 101-110.

Canário, R. (2000). A prática profissional na formação de professores. In B. P. Campos (Org.), Formação profissional de professores no ensino superior (pp. 31-45) Porto: Porto Editora. 
Darling-Hammond, L. (2006). Powerful teacher education: Lessons from exemplary programs. San Francisco, CA: Jossey-Bass.

Figueira, S. (2017). O lugar da prática pedagógica na formação inicial dos educadores de infância nos cursos reorganizados no âmbito do processo de Bolonha (Tese de doutoramento, Instituto da Educação da Universidade de Lisboa). Disponível em http://hdl.handle.net/10451/28332.

Flores, M. (2010). Algumas reflexões em torno da formação inicial de professores. Revista Educação, 33. Disponível em http://revistaseletronicas.pucrs.br/ojs/index.php/faced/ article/view.

Formosinho, J. (2009). Dilemas e tensões da atuação da universidade frente à formação de profissionais de desenvolvimento humano. São Paulo, SP: Pró-Reitoria de Graduação da Universidade de São Paulo. Disponível em http://www.prpg.usp.br/.

Matias, G., \& Vasconcelos, T. (2010). Aprender a ser educador de infância: $O$ processo de supervisão na formação inicial. Revista da Inovação às Práticas, $X(1), 17-41$.

Marcelo G. (1999). Formação de professores para uma mudança educativa. Porto: Porto Editora. 788 Práticas Educativas e Supervisão Pedagógica.

Oliveira-Formosinho, J. (2002). A interação educativa na supervisão de educadores estagiários. Um estudo longitudinal. In J. Oliveira-Formosinho (Org.), A supervisão na formação de professores (Vol. I, pp. 121-143). Porto: Porto Editora.

Roldão, M. C. (2009). Formação de professores na investigação portuguesa: Um olhar sobre a função do professor e o conhecimento profissional. Formação Docente: Revista Brasileira de Pesquisa sobre Formação de Professores, 01(01), 57-70. Disponível em http://formacaodocente.autenticaeditora.com.br.

Santos, A. (2015). Educação infantil e formação de professores: Uma proposta do PIBID de pedagogia. In F. I. Ferreira \& C. I. Anjos (Orgs.), Educação de infância: Formação, identidades e desenvolvimento profissional (pp. 77-92). Santo Tirso: De Facto Editores. 
Vasconcelos, T. (2009). Prática pedagógica sustentada: Cruzamento de saberes e de competências. Lisboa: Colibri.

Zabalza, M. A. (2003). El prácticum en la formación de profesionales universitarios: Principios para una enseñanza de calidad. In Seminario para el Estudio Comparado de la Formación Práctica en el Sistema Universitario (pp. 40-52). Granada, España: [s.n.].

Zeichner, K. (2000). Formação de professores: Contacto direto com a realidade da escola: Entrevista a Kenneth Zeichner. Presença Pedagógica, 6(34), 5-15. Disponível em http://pt.slideshare.net/viviprof/k-zeichner-entrevista. 